\title{
Elective unilateral total knee replacement using continuous femoral nerve blockade versus conventional patient-controlled analgesia: perioperative patient management based on a multidisciplinary pathway
}

\author{
Janet WS Wu *, YC Wong
}

\section{A B S T R A C T}

Objectives: To evaluate the effectiveness of our new multidisciplinary pathway for total knee replacement patients and compare outcomes after continuous femoral nerve blockade versus conventional patientcontrolled analgesia for postoperative pain.

Design: Randomised controlled trial in a routine clinical setting.

Setting: Acute orthopaedic wards and operating theatres, Yan Chai Hospital, Hong Kong.

Patients: Sixty patients underwent elective unilateral total knee replacement under spinal anaesthesia from May 2009 to September 2011 and were randomly assigned to continuous femoral nerve blockade or conventional patient-controlled analgesia (30 patients in each group).

Main outcome measures: Quality of pain control was evaluated by pain scores at rest and during mobilisation, opioid consumption, frequency of sideeffects, and patient satisfaction score. Rehabilitation progress was assessed according to the day of first starting weight-bearing exercise, day of independent walking in the ward with aid, Timed Up and Go test,
This article was published on 11 September 2013 at www.hkmj.org. and time elapsing till discharge. Surgical outcome was assessed by the Knee Society score 6 months after discharge, re-admissions, and occurrence of complications.

blockade tended to have less pain on movement and achieved earlier mobilisation than those having patient-controlled analgesia. The former group consumed less opioids, had fewer side-effects, and were more satisfied with their postoperative analgesia. Both groups showed an equally high degree of satisfaction with the new management pathway. Hospital stays, surgical outcomes, and frequency of complications were similar in the two groups.

Conclusion: Continuous femoral nerve blockade proved to be a feasible and better alternative mode of postoperative analgesia than our conventional patientcontrolled analgesia. Our new multidisciplinary management pathway and multimodal analgesic regimen featuring the continuous femoral nerve blockade appeared beneficial to patients and effective in our clinical setting.

\section{Hong Kong Med J 2014;20:45-51}

DOI: 10.12809/hkmj133899

JWS Wu *, FHKCA, FHKAM (Anaesthesiology)

${ }^{2}$ YC Wong, FHKCOS

Department of Anaesthesia

2 Department of Orthopaedics and Traumatology

Yan Chai Hospital, Tsuen Wan, Hong Kong

Results: Patients having continuous femoral nerve

New knowledge added by this stud

- Levobupivacaine concentration as low as $0.08 \%$ provided adequate analgesia in our patients with minimal muscle weakness and mild numbness.

- Co-ordinated pathways featuring the use of continuous femoral nerve blockade were effective and appreciated by our patients.

Implications for clinical practice or policy

- Work is necessary to identify areas of improvement to shorten hospital stays and hasten recovery without compromising outcomes and wellbeing.

- A multidisciplinary approach to total knee replacement patients can be applied to other surgical groups, for whom suitable studies should be conducted to investigate possible overall benefit.

\section{Introduction}

Total knee replacement (TKR) is commonly performed to reduce chronic pain and improve the functional state of patients suffering from degenerative disease. A favourable patient outcome depends very much on surgical technique, postoperative analgesia, and active mobilisation. All these require input from different specialties and 


\section{使用連續性大腿神經局部麻醉法或傳統的病人 自控鎮痛機進行單側全膝關節置換手術： 跨學科流程於圍手術期間的病人管理}

\section{胡慧珊、黃耀忠}

目的：評估全膝關節置換手術後新跨學科流程的效用, 並比較連續性 大腿神經局部麻醉法和傳統的病人自控鎮痛機的術後止痛效果。

設計：在常規臨床環境下的隨機對照試驗。

安排：香港仁濟醫院的急性骨科病房及手術室。

患者：2009年5月至2011年9月期間, 在脊髓麻醉下接受選擇性單側 全膝關節置換手術的 60 名病人, 他們被隨機分配到連續性大腿神經局 部麻醉組或傳統的病人自控鎮痛組（各30例）。

主要結果測量：根據以下參數評估疼痛控制的效用：休息和行走時的 疼痛評分、嗎啡類藥物用量、副作用的頻率和病人對止痛效果的滿 意度。再根據以下各項評估病人的康復進展：開始進行負重練習的第 一天、病房裡依靠輔助器行走的第一天、起立行走測試及住院所需時 間, 並按出院後6個月的膝關節學會評分、再入院記錄及併發症情況 評估手術結果。

結果：與傳統的病人自控鎮痛組比較, 進行連續性大腿神經局部麻醉 法的病人行走時的痛楚較少, 並較早可以走動; 他們消耗較少嗎啡類 藥物, 副作用較少, 並對術後止痛感到更滿意。兩組對於新的治理流 程同樣感到高度滿意, 其住院、手術結果和併發症次數也相若。

結論：連續性大腿神經局部麻醉對於術後鎮痛是一個可行的方法, 並 且比傳統的病人自控鎮痛方法更好。這種新的跨學科管理模式及多模 式鎮痛方法顯示連續性大腿神經局部麻醉對患者有利和有效。 on optimising acute postoperative pain control).

2. Aggressive physiotherapy with early mobilisation, starting on postoperative day (POD) 1.

3. Active early screening for deep vein thrombosis (DVT) by ultrasonography on PODs 4-5.

4. Monitoring and treatment for complications, ensuring patient safety and satisfaction.

\section{Methods}

This was a randomised controlled trial using a structured questionnaire and data retrieval forms, and was conducted in orthopaedic wards and operating theatres (OTs) in Yan Chai Hospital between May 2009 and September 2011. Prior approval from Kowloon West Cluster Ethics Committee was obtained. The target patients were those who underwent unilateral elective TKR under spinal anaesthesia (SA). Patients unable to communicate, had contra-indications to peripheral nerve blockade, receiving anticoagulation or DVT prophylaxis, and those eventually converted to general anaesthesia or having complicated revision surgery were excluded from the study. A sample size of 60 patients was calculated based on a Power Analysis and Sample Size calculator with a background pain score of $0.6(6 / 10)$, an expected difference of $0.3(3 / 10)$, an alpha of 0.05 (2-sided), and power of 0.8 . These 60 patients were randomised to the CFNB and PCA groups (30 patients in each), using computer-generated random numbers. Subjects were divided into two groups (odd against even numbers generated by the computer). The case allocation was concealed in sealed envelopes and the mode of analgesia revealed to case anaesthetist and patient after the patient was included in the study. No blinding was feasible for ward doctors, nurses, and physiotherapists due to practical constraints (different machine types being placed by the bedside). All cases were managed according to our new multidisciplinary TKR pathway (Appendix 2) and multimodal analgesic regimen (Appendix 1). Data were extracted from the preoperative period till 6 months after discharge from hospital.

For CFNB patients, the relevant catheter was inserted under nerve stimulation and ultrasound guidance, and before the performance of SA inside the OT a correct position was confirmed by the case anaesthetist with ice and ultrasound in the induction/ recovery room. A standardised bolus of $15 \mathrm{~mL} 0.5 \%$ levobupivacaine was injected after insertion of the CFNB catheter. Successful femoral nerve blockade was ensured by testing with ice before performance of SA. Patients were then started on a continuous infusion of 8 to $12 \mathrm{~mL} / \mathrm{h}$ of $0.08 \%$ levobupivacaine postoperatively in the recovery area till POD 3 (4-day infusion regimen) when the catheter was removed (in the ward by an anaesthetist). Regarding the PCA 
patients, they were allowed intravenous morphine after the operation, starting in the recovery area.

Both CFNB and PCA groups were started on a standardised multimodal analgesic regimen (if not contra-indicated) that entailed paracetamol, sustained release diclofenate, opioids (codeine or morphine), and drugs to prevent the side-effects from these analgesics (Appendix 2).

Both patient groups received SA using a 25G Quincke spinal needle and local anaesthetics injected intrathecally to achieve a block of at least T10 for the surgery. Then they underwent TKR using a tourniquet which was inflated to pressures of 250 to $280 \mathrm{~mm} \mathrm{Hg}$ before skin incision. The tourniquet was deflated after bandages were applied at the end of surgery. Cement was used in all cases. A drain was inserted using suction and reviewed by surgeons and ward nurses on POD 1 (during the surgeon's morning round). At that round, decisions were made as to whether the drain could be safely removed, the patient was fit to go for X-ray, and undergo mobilisation in the ward on that day (under supervision of the physiotherapist). Thereafter, the physiotherapist assessed the patient's fitness to step up the intensity of exercise in the ward and then in the gymnasium of the Department of Physiotherapy (without monitoring by a nurse). Until discharge, each patient's pain intensity and complications were monitored closely by ward nurses and surgeons.

Routine ultrasound screening was performed on PODs 4-5 to detect the early occurrence of DVT. All patients had sequential leg compressors applied and started on early mobilisation postoperatively from POD 1 if possible (to prevent DVT).

Data were collected on the quality of pain control (pain scores on visual analogue scale [VAS] of 1-10 at rest and during mobilisation, supervised by physiotherapist), opioid consumption and the frequency of side-effects (by ward nurse and anaesthetist doing pain rounds twice per day), patient satisfaction score (VAS 1-10 on the quality of analgesia by the pain anaesthetist), and discontinuation of PCA or CFNB. The progress of rehabilitation (from the day of mobilisation and independent walking in the ward), the Timed Up and Go test (conducted by the physiotherapist), and surgical outcomes were also recorded. Surgical outcomes entailed Knee Society scores (assessed preoperatively, upon discharge, and then 6 weeks and 6 months after discharge), complications, re-admissions, and mortality (all assessed by orthopaedic surgeons). All data were analysed using the Statistical Package for the Social Sciences (Windows version 10.0; SPSS Inc, Chicago [IL], US), and outcome measures were compared using Student's $t$ tests and Chi squared tests.

\section{Results}

In all, 79 patients were recruited but 19 were excluded for various reasons (Box), and replacements were recruited using the permuted block technique. Eventually 30 patients each were recruited as the CFNB and PCA groups. Basic demographic data, intra-operative surgical and anaesthetic parameters in the two groups were similar (Table 1).

Regarding the quality of pain control, the CFNB patients tended to have lower pain scores during mobilisation on PODs 1 and 2 than those in the PCA group (Table 2), but their pain scores at rest were similar. For the sake of comparison, opioid consumption of each patient was converted to equivalent dosages of intravenous morphine. On this basis, the CFNB group consumed significantly less opioid than the PCA group only on PODs 0-1 $(\mathrm{P}<0.05)$, but more opioid on POD 3 (Table 2). Fewer patients suffered from opioid side-effects in the CFNB than PCA group on all PODs (nausea and/or vomiting $27 \%$ vs $63 \%$, and dizziness $17 \%$ vs 40\%; $\mathrm{P}<0.05$ for both; Table 3 ). Mild catheter site oozing and mild limb numbness were reported in about one third of the CFNB patients. Notably, nonsteroidal anti-inflammatory drug (NSAID)-related complications were rare in both groups. Patients were more satisfied with the quality of pain control by CFNB than PCA (Table 4; $\mathrm{P}=0.05$ ). More patients would use the same form of postoperative analgesia again for TKR in the CFNB than PCA group (67\% vs $50 \%$, respectively).

Concerning rehabilitation, more CFNB than PCA patients started mobilisation on POD $1(83 \%$ vs $50 \%$, respectively, $\mathrm{P}=0.012$; Table 5$)$. The mean day of independent walking in the ward was also earlier (POD 6 vs 8; P=0.047). Significant dizziness, and nausea and vomiting were the main reasons for delayed early mobilisation in the PCA group. We were unable to draw conclusions for the Timed Up and Go test because of missing data (30\%). No accidental fall, injury, or complaint was reported throughout the study period.

Regarding surgical outcomes, the mean duration of hospitalisation, in-hospital surgical

BOX. Excluded cases and reasons for exclusion

Patient-controlled analgesia ( $\mathbf{n}=9$ )
Preoperative myocardial infarction (1)
Failed spinal anaesthesia (4)
Postoperative atrial fibrillation + confusion (1)
Pulmonary embolism (1)
Medically not fit (1)
Changed to unicompartmental knee arthroplasty (1)
Continuous femoral nerve blockade ( $\mathbf{n = 1 0 )}$
Sepsis (1)
Infusion stopped (1)
Catheter out (1)
Converted to general anaesthesia (4)
Failed continuous femoral nerve blockade (1)
Shock requiring admission to intensive care unit (1)
Manpower limits (1)


TABLE I. Basic demographics, and surgical and anaesthetic details of the continuous femoral nerve blockade (CFNB) and conventional patient-controlled anaesthesia (PCA) groups

\begin{tabular}{|c|c|c|c|}
\hline \multirow[t]{2}{*}{ Demographics/details } & \multicolumn{2}{|c|}{ Mean \pm standard deviation or No. of patients } & \multirow[t]{2}{*}{ P value ${ }^{*}$} \\
\hline & PCA & CFNB & \\
\hline Age (years) & $68.9 \pm 7.5$ & $68.8 \pm 6.4$ & 0.94 \\
\hline Sex & & & 1.00 \\
\hline Female & 22 & 22 & \\
\hline Male & 8 & 8 & \\
\hline ASA & & & 0.402 \\
\hline 1 & 5 & 4 & \\
\hline 2 & 24 & 23 & \\
\hline 3 & 1 & 3 & \\
\hline Body mass index $\left(\mathrm{kg} / \mathrm{m}^{2}\right)$ & $28.3 \pm 5.7$ & $27.8 \pm 3.9$ & 0.402 \\
\hline Smoking & & & 0.141 \\
\hline Non-smoker & 25 & 28 & \\
\hline Current smoker & 0 & 1 & \\
\hline Ex-smoker & 5 & 1 & \\
\hline Drinking & & & 0.699 \\
\hline Non-drinker & 28 & 28 & \\
\hline Current drinker & 1 & 2 & \\
\hline Ex-drinker & 1 & 0 & \\
\hline Diagnosis & & & 0.317 \\
\hline Osteoarthritis & 30 & 29 & \\
\hline Rheumatoid arthritis & 0 & 1 & \\
\hline Operation duration (mins) & $121.1 \pm 27.7$ & $116.5 \pm 31.3$ & 0.549 \\
\hline Tourniquet time (mins) & $100.1 \pm 21.3$ & $95.0 \pm 22.6$ & 0.372 \\
\hline \multicolumn{4}{|l|}{ Blood loss (mL) } \\
\hline Intra-operative & $91.3 \pm 102.2$ & $86.0 \pm 50.9$ & 0.9 \\
\hline Perioperative & $394.0 \pm 267.0$ & $434.0 \pm 309.0$ & 0.604 \\
\hline Local anaesthetics used & & & - \\
\hline Heavy marcaine & 30 & 28 & \\
\hline Levobupivacaine & 0 & 1 & \\
\hline Plain marcaine & 0 & 1 & \\
\hline Volume of LA used for $S A(m L)$ & $2.5 \pm 0.3$ & $2.6 \pm 0.3$ & 0.257 \\
\hline SA block level & $\mathrm{T} 8.4 \pm 2.3$ & $\mathrm{~T} 8.5 \pm 1.9$ & 0.901 \\
\hline Transfusion & 0 & 0 & \\
\hline Vital sign instability & $\begin{array}{c}2 \text { (Shock-like state responded to } \\
\text { intravenous fluid) }\end{array}$ & $\begin{array}{l}2 \text { (Shock-like state responded to } \\
\text { intravenous fluid) }\end{array}$ & \\
\hline
\end{tabular}

Abbreviations: $A S A=$ American Society of Anesthesiologists; $L A=$ local anaesthesia; $S A=$ spinal anaesthesia

* Student's $t$ test

complications (bleeding, DVT, sepsis, etc) and Knee Society score and functional score changes from the preoperative period till the 6-month follow-up were similar in both groups (Table 6). In all, DVT was detected in five patients (on PODs 4-5): three were in the PCA group (2 had a body mass index [BMI] of $\left.>36 \mathrm{~kg} / \mathrm{m}^{2}\right)$. There was no other known predisposing factor for DVT in either group, and no pulmonary embolism or mortality was reported. Surgica infection occurred in two patients ( 1 in each group), for which they underwent re-operation.

As to the efficiency of our new TKR pathway, introduction of CFNB analgesia caused only a minimal effect on case turnover, as such cases were sent to the OT earlier to allow prior performance of the CFNB that was tested in the recovery/ induction area before the previous case ended. The mean waiting time pending transferral to the 
OT after CFNB insertion was 28 minutes, and the mean discharge time from the OT to the recovery area was 6 minutes. Performance of the nerve block entailed a mean time of 32 minutes (all performed or supervised by anaesthesia specialists). After the operation, however, the CFNB group remained significantly longer in the recovery area (62 vs 46 minutes, $\mathrm{P}=0.014)$. No major mishap and/or patient complication (accidental fall, chronic neuropathic pain, or mortality) was reported. Both groups reported equally high satisfaction scores for our new TKR pathway (>9/10, $\mathrm{P}=0.791$; Table 4$)$.

\section{Discussion}

For TKR patients, our results showed favourable analgesic outcomes with the use of CFNB as compared to conventional PCA. The former was associated with lower pain scores during mobilisation (not at rest) and reduced opioid consumption and corresponding side-effects, which agreed well with previous studies. ${ }^{8,12}$ A larger sample size or further addition of new analgesics to our current regimen may be necessary to reveal a statistically significant difference in pain scores. Significantly more patients were able to mobilise on POD 1 in the CFNB group, which achieved better patient morale, and a sense of control and satisfaction. Earlier mobilisation was made possible due to better analgesia by CFNB and its opioid-sparing effect caused fewer distressing sideeffects (nausea, vomiting, and dizziness). However, there was possible unintended over-treatment with opioids in the CFNB group from PODs 2-3 (when pain intensity had dropped markedly). Modifications were considered either to reduce the standard opioid dosage or attempt earlier removal of the catheter (on POD 2 instead of 3) so as to facilitate earlier aggressive exercise in the physiotherapy gymnasium. On the contrary, the PCA patients were less satisfied with quality of pain control; most of their distress being due to opioid-related side-effects that hindered activation and interfered with mobilisation on POD 1 . There may have been under-utilisation of opioids in both groups, because the patients choose not to activate for further morphine boluses to avoid nausea/vomiting and dizziness despite moderate pain; but the extent of this effect was not estimated. In about two thirds of patients in both groups, NSAIDs were prescribed and transient renal impairment on POD 4 warranted stopping them in a few instances. Routine monitoring of renal function on POD 3 was not indicated, given our limited period of NSAID prescription (4 days) and the low frequency of renal impairment on POD 4.

Rehabilitation appeared to be faster with CFNB. No accidental dislodgement of CFNB/PCA catheters or patient injury was reported during physiotherapy with the machines and catheters in situ. The PCA group started independent walking
TABLE 2. Maximum pain scores at rest and during mobilisation, and opioid consumption of the continuous femoral nerve blockade (CFNB) and conventional patient-controlled anaesthesia (PCA) groups

\begin{tabular}{|c|c|c|c|}
\hline \multirow[t]{2}{*}{ Postoperative day } & \multicolumn{2}{|c|}{ Mean \pm standard deviation } & \multirow[t]{2}{*}{ P value } \\
\hline & PCA & CFNB & \\
\hline \multicolumn{4}{|l|}{ Pain score at rest } \\
\hline 0 & $5.4 \pm 1.7$ & $5.1 \pm 2.6$ & 0.553 \\
\hline 1 & $4.0 \pm 1.3$ & $4.1 \pm 1.8$ & 0.935 \\
\hline 2 & $3.2 \pm 1.1$ & $3.2 \pm 1.4$ & 0.840 \\
\hline 3 & $2.9 \pm 1.2$ & $2.8 \pm 1.4$ & 0.844 \\
\hline \multicolumn{4}{|c|}{ Pain score during mobilisation } \\
\hline 0 & N/A† & N/A & \\
\hline 1 & $7.1 \pm 2.3$ & $6.1 \pm 2.9$ & 0.265 \\
\hline 2 & $4.3 \pm 2.8$ & $4.0 \pm 2.4$ & 0.658 \\
\hline 3 & $2.6 \pm 2.4$ & $2.7 \pm 2.3$ & 0.867 \\
\hline \multicolumn{4}{|c|}{ Morphine dose consumption* } \\
\hline 0 & $15.5 \pm 8.9$ & $3.1 \pm 2.1$ & $<0.0001$ \\
\hline 1 & $10.7 \pm 10.1$ & $6.1 \pm 0.9$ & 0.021 \\
\hline 2 & $5.3 \pm 7.7$ & $5.2 \pm 1.4$ & 0.947 \\
\hline 3 & $1.6 \pm 2.9$ & $3.4 \pm 1.6$ & 0.006 \\
\hline
\end{tabular}

Expressed as mg of intravenous morphine equivalent

+ N/A denotes not applicable as patient attempted first mobilisation on postoperative day I

$\neq$ Student's t test

TABLE 3. Opioid side-effects in the continuous femoral nerve blockade (CFNB) and conventional patient-controlled anaesthesia (PCA) groups

\begin{tabular}{lcl}
\hline Opioid side-effects (postoperative days 0-2) & \multicolumn{1}{c}{ PCA } & \multicolumn{1}{c}{ CFNB } \\
\hline Nausea and/or vomiting & $19(63 \%)$ & $8(27 \%)$ \\
\hline Acute retention of urine requiring catheterization & $8(27 \%)$ & $3(10 \%)$ \\
Dizziness & $12(40 \%)$ & $5(17 \%)$ \\
Postoperative shock & $2(7 \%)$ & $3(10 \%)$ \\
Renal impairment (rise of creatinine above baseline) & $2(7 \%)$ & $2(7 \%)$ \\
Desaturation (warranting oxygen supplementation) & $1(3 \%)$ & 0 \\
Constipation & 0 & 0 \\
\hline
\end{tabular}

TABLE 4. Patients' satisfaction score upon discharge from hospital of the continuous femoral nerve blockade (CFNB) and conventional patient-controlled anaesthesia (PCA) groups

\begin{tabular}{lcc}
\hline Group & \multicolumn{2}{c}{ Mean \pm standard deviation } \\
\cline { 2 - 3 } & $\begin{array}{c}\text { Satisfaction towards pain } \\
\text { control }\end{array}$ & $\begin{array}{c}\text { Satisfaction towards total } \\
\text { knee replacement pathway }\end{array}$ \\
\hline PCA & $7.2 \pm 2.3$ & $9.3 \pm 1.0$ \\
CFNB & $8.3 \pm 2.0$ & $9.4 \pm 1.3$ \\
& $\mathrm{P}=0.05^{\star}$ & $\mathrm{P}=0.791^{\star}$ \\
\hline
\end{tabular}

Student's $t$ test 
in the ward earlier than CFNB group was possibly due to unavailability of services during weekends and public holidays. This manpower limitation may have affected less than $10 \%$ of our subjects, and was overcome in the middle of the study, when surgeons allocated more TKRs to be performed earlier in the week to facilitate continued physiotherapy in the immediate postoperative period. Long-term outcomes were similar as reflected by knee score changes. Mobility and function were both improved. Most patients were taking only simple analgesics (eg paracetamol as required) for any residual pain.

In both groups, DVT occurred in a minority of cases, with a frequency similar to that usually encountered in our hospital (8-10\%). All subjects were encouraged to mobilise early to minimise DVT and foot pumps were applied from POD 0; two patients in PCA group were extremely obese $\left(\mathrm{BMI}>36 \mathrm{~kg} / \mathrm{m}^{2}\right)$. In such patients, there may be co-

TABLE 5. Day of starting mobilisation of the continuous femoral nerve blockade (CFNB) and conventional patientcontrolled anaesthesia (PCA) groups

\begin{tabular}{lcc}
\hline $\begin{array}{l}\text { First mobilisation on } \\
\text { postoperative day }\end{array}$ & PCA & CFNB \\
\hline 1 & 15 & $25^{*}$ \\
2 & 13 & 5 \\
3 & 2 & 0 \\
\hline$*$ Data analysed using Chi squared test; $\mathrm{X}_{2}=8.783, \mathrm{P}=0.012$
\end{tabular}

existing obstructive sleep apnoea and cardiovascular problems that warrant intensive care unit monitoring. However, beds may not always be available for such elective cases, resulting in unwanted cancellations on the proposed day of surgery. The role of CFNB, $\mathrm{SA}$, and multimodal analgesics appear essential in this situation, so as to facilitate opioid sparing and reduce respiratory depression in the general ward while providing safer and better analgesia than PCA morphine. With better co-ordination, CFNB can be safely used and removed with concomitant use of low-molecular-weight heparin in high-risk cases. After our study, local guidelines have evolved to offer such patients regional blocks together with anticoagulation.

The work logistics with the introduction of CFNB to our TKR patients were efficient and different carers co-ordinated well to minimise disturbance to OT turnover and ensure patient safety and comfort during the whole process of rehabilitation. Despite achieving earlier mobilisation, we were unable to attain hospital stays shorter than 13 to 14 days (our pre-study standard), which was mostly for social reasons including lack of home carers, proper assistance for safe rehabilitation at home, personnel to bring patients back for out-patient follow-up and physiotherapy. Further collaboration with occupational therapists and social workers and preoperative psychosocial preparation for patients and their families in the new pre-admission clinic are essential, with a view

TABLE 6. Summary of surgical outcomes of the continuous femoral nerve blockade (CFNB) and conventional patient-controlled anaesthesia (PCA) groups

\begin{tabular}{|c|c|c|c|}
\hline Surgical outcome & PCA & CFNB & $P$ value \\
\hline Mean duration of hospitalisation (days) ${ }^{\star}$ & 13.6 & 13.5 & 0.910 \\
\hline Postoperative surgical complication: deep vein thrombosis & 3 & 2 & - \\
\hline Bleeding requiring transfusion & 3 & 2 & - \\
\hline Shock in ward & 2 & 3 & - \\
\hline Wound infection & 1 & 1 (Readmit) & - \\
\hline Mortality & 0 & 0 & - \\
\hline \multicolumn{4}{|c|}{ Knee Society score compared with preoperative value after discharge $†$} \\
\hline Upon discharge & +19.70 & +23.57 & 0.562 \\
\hline At 6 weeks & +37.9 & +40.2 & 0.715 \\
\hline At 3 months & +42.87 & +44.63 & 0.780 \\
\hline At 6 months & +44.7 & +48.73 & 0.513 \\
\hline \multicolumn{4}{|c|}{ Functional score compared with preoperative value after discharge $†$} \\
\hline Upon discharge & -15.5 & -18.83 & 0.550 \\
\hline At 6 weeks & +2.33 & 0 & 0.679 \\
\hline At 3 months & +16 & +13.93 & 0.717 \\
\hline At 6 months & +20.33 & +25.17 & 0.392 \\
\hline
\end{tabular}


to reducing hospital stays while ensuring patient satisfaction and safety.

\section{Sources of error}

Selection bias may have occurred when 19 patients were excluded from the original sample and may not have had the same demographic profile as their replacements (Table 1). When assessing for pain and satisfaction scores, measurement bias may have ensued when different ward nurses, anaesthetists, and physiotherapists asked patients at different times despite all of them having been instructed to ask questions in the same way in Cantonese and using the same VAS for comparison. Reported pain scores may also be affected by other similar patients nearby, and the carers not blinded to the mode of patient analgesia. The effect of self-withholding of opioids due to undesirable side-effect was not estimated (in both groups). Recall bias can occur when patients are asked about their satisfaction with our TKR pathway, as some may have left hospital already and the anaesthetist could only call them for assessment after discharge. Complete blinding of investigators and assessors was not possible in our setting, as the PCA and CFNB machines had very different appearances and were mounted near the bedside to facilitate easier and safer clinical care of analgesia.

\section{Acknowledgements}

Special thanks to the many dedicated colleagues from the Department of Anaesthesia, Orthopaedics and Traumatology, nursing teams of both orthopaedic wards and operating theatres, Physiotherapy, Occupational Therapy, social workers and preadmission clinic nurses and staff who put in much effort to improve our service delivery and quality to achieve better patient outcomes.

\section{Appendices}

Additional material related to this article can be found on the HKMJ website. Please go to <http:// www.hkmj.org>, search for the appropriate article, and click on Full Article in PDF following the title.

\section{References}

1. Ranawat CS, Ranawat AS, Mehta A. Total knee arthroplasty rehabilitation protocol: what makes the difference? J Arthroplasty 2003;18(3 Suppl 1):27S-30S.

2. Kim S, Losina E, Solomon DH, Wright J, Katz JN. Effectiveness of clinical pathways for total knee and total hip arthroplasty: literature review. J Arthroplasty 2003;18:69-74.
3. Yasunaga $\mathrm{H}$, Tsuchiya $\mathrm{K}$, Matsuyama $\mathrm{Y}$, Ohe K. Analysis of factors affecting operating time, postoperative complications, and length of stay for total knee arthroplasty: nationwide web-based survey. J Orthop Sci 2009;14:106.

4. Larsen K, Sørensen OG, Hansen TB, Thomsen PB, Søballe K. Accelerated perioperative care and rehabilitation intervention for hip and knee replacement is effective: a randomized clinical trial involving 87 patients with 3 months of follow up. Acta Orthop 2008;79:149-59.

5. Department recommendation for pain control in total knee replacement (TKR) surgery (1/7/2010). Hong Kong: Department of Anaesthesia and Intensive Care, Tuen Mun Hospital; 2010.

6. Clinical pathway-total knee replacement. Jan 2009. Ontario, Canada: The Credit Valley Hospital; 2009.

7. Walter FL, Bass N, Bock G, Markel DC. Success of clinical pathways for total joint arthroplasty in a community hospital. Clin Orthop Relat Res 2007;457:133-7.

8. Paul JE, Arya A, Hurlburt L, et al. Femoral nerve block improves analgesia outcome in total knee replacement. Anesthesiology 2010;113:1144-62.

9. Chu CP, Yap JC, Chen PP, Hung HH. Postoperative outcome in Chinese patients having primary total knee arthroplasty under general anaesthesia/intravenous patient-controlled analgesia compared to spinal-epidural anaesthesia/analgesia. Hong Kong Med J 2006;12:442-7.

10. Chelly JE, Greger J, Gebhard R, et al. Continuous femoral blocks improve recovery and outcome of patients undergoing total knee arthroplasty. J Arthroplasty 2001;16:436-45.

11. Ilfeld BM, Le LT, Meyer RS, et al. Ambulatory continuous femoral nerve blocks decrease time to discharge readiness after tricompartment total knee arthroplasty: a randomized, triple-masked, placebo-controlled study. Anesthesiology 2008;108:703-13.

12. Ilfeld BM, Mariano ER, Girard PJ, et al. A multicenter, randomized, triple-masked, placebo-controlled trial of the effect of ambulatory continuous femoral nerve blocks on discharge readiness following total knee arthroplasty in patients on general orthopedic wards. Pain 2010;150:47784.

13. Carli F, Clemente A, Asenjo JF, et al. Analgesia and functional outcome after total knee arthroplasty: periarticular infiltration vs continuous femoral nerve block. Br J Anaesth 2010;105:185-95.

14. Hebl JR, Dilger JA, Byer DE, et al. A pre-emptive multimodal pathway featuring peripheral nerve block improves perioperative outcomes after major orthopedic surgery. Reg Anesth Pain Med 2008;33:510-7.

15. Parvataneni HK, Shah VP, Howard H, Cole N, Ranawat AS, Ranawat CS. Controlling pain after total hip and knee arthroplasty using a multimodal protocol with local periarticular injections: a prospective randomized study. J Arthoplasty 2007;22(6 Suppl 2):33S-38S.

16. Fischer HB, Simanski CJ, Sharp C, et al. A procedure-specific systematic review and consensus recommendations for postoperative analgesia following total knee arthroplasty. Anaesthesia 2008;63:1105-23. 


\section{APPENDIX I. Multimodal analgesic regimen for elective total knee replacement patients during study period}

BD denotes twice a day, CFNB continuous femoral nerve blockade, Cl contra-indication, Cx complication, FU follow-up, IMI intramuscular injection, iv intravenous, obs observation, OSAS obstructive sleep apnoea syndrome, OT operating theatre, PAC preadmission clinic, PCA patient-controlled analgesia, po orally, POD postoperative day, prn as needed, Q4H every 4 hours, Q6H every 6 hours, Q8H every 8 hours, QID 4 times a day, physio physiotherapy, and stat drug to be given at this moment

\begin{tabular}{|c|c|c|}
\hline POD & CFNB & PCA \\
\hline 0 & 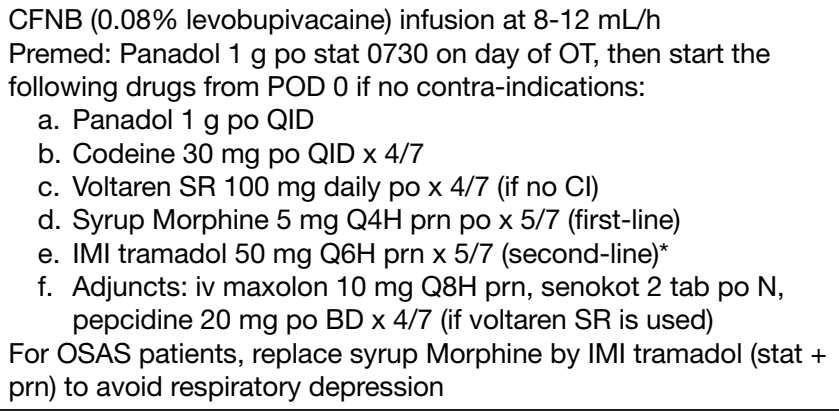 & $\begin{array}{l}\text { PCA Morphine } 1 \mathrm{mg} \text { bolus, lockout } 5 \mathrm{~min}, 30 \mathrm{mg} \text { in } 4 \mathrm{~h} \text { (modify in } \\
\text { OSAS patients) } \\
\text { Premed: Panadol } 1 \mathrm{~g} \text { po stat } 0730 \text { on day of OT, then } \\
\text { a. Panadol } 1 \mathrm{~g} \text { po QID } \\
\text { b. Voltaren SR } 100 \mathrm{mg} \text { daily po x } 4 / 7 \text { (if no } \mathrm{Cl} \text { ) } \\
\text { c. Adjuncts: iv maxolon, senokot, pepcidine (if Voltaren SR is } \\
\quad \text { used) } \\
\text { Continue PCA according to usual protocol } \\
\text { For both groups, chart pain scores at rest (pain obs form) and during } \\
\text { mobilisation (on physio form) }\end{array}$ \\
\hline 1 & $\begin{array}{l}\text { - Syrup Morphine } 5 \mathrm{mg} \text { po stat at } 0930 \text { for physio to start at } 1030 \\
\text { - Continue CFNB during physio } \\
\text { - Check for excessive bleeding \& Cx }\end{array}$ & $\begin{array}{l}\text { - Continue PCA and multimodal regimen } \\
\text { - Check for excessive bleeding \& Cx }\end{array}$ \\
\hline 2 & $\begin{array}{l}\text { - Syrup Morphine } 5 \mathrm{mg} \text { po stat at } 0930 \text { for physio } \\
\text { - Continue CFNB during physio } \\
\text { - Continue multimodal regimen as charted } \pm \text { modify }\end{array}$ & $\begin{array}{l}\text { - Continue PCA and multimodal regimen as charted } \pm \text { modify } \\
\text { - Check patient } \mathrm{Cx} \text { and satisfaction }\end{array}$ \\
\hline 3 & $\begin{array}{l}\text { - Off CFNB catheter } \\
\text { - Check for CFNB Cx and satisfaction } 1 \mathrm{~d} \text { after catheter off } \\
-\quad \pm \text { Arrange PAC FU }\end{array}$ & $\begin{array}{l}\text { - OFF PCA } \\
\text { - Check patient Cx and satisfaction }\end{array}$ \\
\hline
\end{tabular}

* Tramadol (IMI) prn can be used if: (1) severe unresolved pain 1 hour after last syrup Morphine intake; (2) repeated vomiting after syrup Morphine intake; and (3) patients at risk of respiratory depression if given syrup Morphine (eg obstructive sleep apnoea syndrome) Notes:

1. Syrup Morphine (stat dose at 0930) may be omitted if last dose is given within 2 hours in CFNB group.

2. In case of severe uncontrolled pain or PNB complication (eg block failure) in CFNB group, PCA may be prescribed after anaesthetist's assessment (subjects will be excluded from study).

3. Anaesthetist may modify analgesic regimen to cater for individual patient's needs (eg OSAS), CROSS OUT drugs that are not suitable in pre-printed drugs sheets in OT to avoid confusion. 


\section{APPENDIX 2. Multimodal analgesic regimen + multidisciplinary protocol for patients undergoing total knee replacement during study period}

CFNB denotes continuous femoral nerve blockade, $\mathrm{Cl}$ contra-indication, $\mathrm{CPM}$ continuous passive movement machine, $\mathrm{Cx}$ complication, DVT deep vein thrombosis, FU follow-up, im intramuscular, LA local anaesthetic, N/V nausea and vomiting, obs observation, OT operating theatre, PAC preadmission clinic, PCA patient-controlled analgesia, po orally, POD postoperative day, prn as needed, Q4H every 4 hours, Q6H every 6 hours, QID 4 times a day, reg regular doses, RFT renal function test, r/o removal of, physio physiotherapy, stat drug to be given at this moment, syr syrup, tx treatment, and XR X-ray

\begin{tabular}{|c|c|c|c|c|c|}
\hline POD & $\begin{array}{l}\text { Anaesthetist (CFNB } \\
\text { infusion) }\end{array}$ & Anaesthetist (PCA) & Orthopaedic surgeon & Physiotherapist & Ward nurse \\
\hline 0 & $\begin{array}{l}\text { - Femoral nerve catheter } \\
\text { infusion: } 8-12 \mathrm{~mL} / \mathrm{h} \\
\text { - Premed: Panadol } 1 \mathrm{~g} \\
\text { po stat } 0730 \text { on OT day, } \\
\text { then Panadol } 1 \mathrm{~g} \text { po } \\
\text { QID, Codeine } 30 \mathrm{mg} \\
\text { po QID x 4/7, Voltaren } \\
\text { SR } 100 \mathrm{mg} \text { daily po x } \\
\text { 4/7, syr Morphine } 5 \mathrm{mg} \\
\text { po Q4H prn x } 5 / 7, \mathrm{im} \\
\text { tramadol } 50 \text { mg Q6H } \\
\text { prn (if Morphine N/V) x } \\
5 / 7 \\
\text { Adjuncts: maxolon, } \\
\text { senokot, pepcidine } \\
\text { - Give stat syr Morphine } 5 \\
\text { mg po at } 0930 \text { on PODs } \\
\text { 1-2 for physio at } 1030 \\
\text { (withhold if <2 h last } \\
\text { dose) }\end{array}$ & $\begin{array}{l}\text { - PCA as prescribed } \\
\text { - Premed: Panadol } 1 \mathrm{~g} \\
\text { po stat } 0730 \text { on OT day } \\
\text { - Panadol } 1 \mathrm{~g} \text { po QID, } \\
\text { Voltaren SR } 100 \mathrm{mg} \\
\text { daily po x } 4 / 7 \text { (if no Cl) } \\
\text { Adjuncts: maxolon, } \\
\text { senokot, pepcidine }\end{array}$ & $\begin{array}{l}\text { - Send physio form } \\
\text { - Monitor blood loss + } \\
\text { resuscitation + foot } \\
\text { pump/CPM }\end{array}$ & $\begin{array}{l}\text { - Preop assessment and } \\
\text { education } \\
\text { - Start physio in bed if } \\
\text { possible } \\
\text { - Chart maximum pain } \\
\text { score during physio on } \\
\text { physio form (POD 0-3) }\end{array}$ & $\begin{array}{l}\text { - Chart on NEW pain obs } \\
\text { form (for both groups, } \\
\text { including pain score at } \\
\text { rest and muscle power) } \\
\text { - Keep pain score at rest } \\
<5 / 10 \text { with reg+prn tx } \\
\text { - Notify anaesthetist \& } \\
\text { physiotherapist during } \\
\text { rounds if persistent } \\
\text { quadriceps power } \leq 2 / 5 \\
\text { or excessive pain }\end{array}$ \\
\hline 1 & $\begin{array}{l}\text { - Check analgesia \& } \\
\text { muscle power ( } \pm \text { adjust/ } \\
\text { stop infusion for physio) } \\
\text { - Check CFNB infusion \& } \\
\text { site } \\
\text { - Check for excessive } \\
\text { bleeding \& Cx (due to } \\
\text { analgesics) }\end{array}$ & $\begin{array}{l}\text { - Check for excessive } \\
\text { bleeding \& Cx due to } \\
\text { analgesics }\end{array}$ & $\begin{array}{l}\text { - Assess for safety of } \\
\text { r/o drains + XR knee } \\
\text { (morning round) } \\
\text { - Assess fitness for } \\
\text { standing \& sit out (am } \\
\text { physio) [XR may be } \\
\text { done in afternoon] } \\
\text { - Monitor blood loss }\end{array}$ & $\begin{array}{l}\text { - Arrive in ward at } 1030 \\
\text { - Assess fitness to } \\
\text { standing \& sit out } \\
\text { - Consult anaesthetist } \\
\text { if muscle power } \leq 2 / 5 \\
\text { hindering physio ( } \pm \\
\text { adjust infusion of } \\
\text { CFNB) } \\
\text { - Continue CFNB } \\
\text { infusion/PCA while } \\
\text { physio } \\
\text { - Fall prevention }\end{array}$ & $\begin{array}{l}\text { - Assist standing \& sit out } \\
\text { - Change dressing (leak) } \\
\text { and off drain if surgeon } \\
\text { ordered } \\
\text { - Continue to chart on } \\
\text { NEW pain obs form }\end{array}$ \\
\hline 2 & $\begin{array}{l}\text { - Continue CFNB infusion } \\
\pm \text { renew LA solution }\end{array}$ & $\begin{array}{l}\text { - Continue PCA } \\
\text { - Check Cx \& satisfaction }\end{array}$ & $\begin{array}{l}\text { - Assess fitness to } \\
\text { increase weight-bearing } \\
\text { exercise/physio in } \\
\text { ward/gym }\end{array}$ & $\begin{array}{l}\text { - Continue physio in } \\
\text { ward with PCAVCFNB in } \\
\text { situ }\end{array}$ & $\begin{array}{l}\text { - Charting for CFNB and } \\
\text { PCA obs }\end{array}$ \\
\hline 3 & $\begin{array}{l}\text { - OFF CFNB catheter } \\
- \pm \text { Arrange PAC FU for } \\
\text { Cx }\end{array}$ & $\begin{array}{l}\text { - OFF PCA (if not off) } \\
\text { - Check Cx and } \\
\text { satisfaction }\end{array}$ & $\begin{array}{l}\text { - Assess fitness for } \\
\text { physio in gym (after } \\
\text { PCA/CFNB off) } \\
\text { - } \pm \text { Modify analgesics }\end{array}$ & $\begin{array}{l}\text { - To gym exercise if fit \& } \\
\text { CFNB/PCA off } \\
\text { - Inform if excessive pain }\end{array}$ & $\begin{array}{l}\text { - CFNB special obs stop } \\
\text { - Continue usual obs for } \\
\text { PCA } \\
\text { - Inform doctor of Cx }\end{array}$ \\
\hline 4 & $\begin{array}{l}\text { - Check for CFNB site Cx } \\
\text { \& satisfaction }\end{array}$ & - & $\begin{array}{l}\text { - DVT scan } \\
\text { - Routine RFT screen }\end{array}$ & $\begin{array}{l}\text { - Continue physio with } \\
\text { discharge plan }\end{array}$ & - \\
\hline
\end{tabular}

